\title{
How Far Can We Take Vessel Wall MRI for Intracranial Atherosclerosis? The Tissue is Still the Issue
}

W e read with great interest the recent article by Zwartbol et $\mathrm{al}^{1}$, and the accompanying commentary by Dr Chan. ${ }^{2}$ While the data from the SMART-MR cohort add to the body of research on intracranial vessel wall MR imaging (vwMRI) studies, we have concerns with the interpretation of the results, specifically that the findings do not support "a different etiology" between intracranial (ICAD) and extracranial (ECAD) atherosclerosis. While vwMRI allows us to visualize disease in the vessel walls themselves, this provides only a snapshot of a dynamic process (atherogenesis) that is years-to-decades in the making. We are far from being able to see underlying processes at a molecular and tissue level that lead to these vwMRI findings.

Since the Virchow era, it has been understood that the distribution of atherosclerosis is not uniform; plaques occur primarily at bifurcations, in curved segments, and in coronary arteries. Intracranial and extracranial arterial systems are derived from different germ cell layers, ectoderm and mesoderm, respectively, and have distinct structural elements and physiologic flow characteristics. ${ }^{3}$ Accordingly, the risk factors for the development of ECAD and ICAD differ with respect to systemic processes like hyperlipidemia, hyperglycemia, or hypertension. Furthermore, atherosclerosis causes symptoms through different mechanisms and recurrence rates by site. As providers who are often frustrated by suboptimal treatment options for ICAD, we can confirm what has been known for decades, that atherosclerosis responds to treatment differently depending on location. Indeed, Dr Chan cites a seminal manuscript from $1964 .^{4}$ Pathophysiologic mechanisms must be taken into account when considering what is seen on imaging.

The association between ICAD and general vascular risk factors examined in Zwartbol et $\mathrm{al}^{1}$ has previously been identified. A major limitation of these factors is over-reliance on stenosis. Prior work suggests that high-grade stenosis in ICAD is a feature of late-stage disease, and algorithms relying on stenosis measurement alone can ignore nonstenotic-but-clinically-active disease. A major benefit of vwMRI is the ability to identify plaque features

- Indicates open access to non-subscribers at www.ajnr.org

http://dx.doi.org/10.3174/ajnr.A6501 like remodeling pattern, enhancement, fibrous cap thickness, proximity to perforator ostia, intraplaque hemorrhage, or lipidrich necrotic core volume. Using vwMRI to merely identify the presence of ICAD misses an opportunity to better characterize the disease.

Another limitation of the methodology in Zwartbol et $\mathrm{al}^{1}$ is identification of ICAD burden regardless of symptomatology. The prevalence of ICAD is rather high, but most lesions prove harmless. The advantage of the granularity of vwMRI is that it could potentially distinguish the multiple ways ICAD can cause ischemic strokes and possibly predict which ICAD plaques are most likely to cause stroke, regardless of level of stenosis. This study also evaluates ICAD and ECAD cross-sectionally, without any clarification of the temporal relationship of disease development in each vascular bed. In addition, there is no indication of ethnicities within the study cohort of 130 patients; certain ethnic populations preferentially develop atherosclerosis in different vascular beds.

This critique is not meant to disparage the work of Zwartbol et $\mathrm{al}^{1}$ or the fine research conducted by the UCCSMART study group. However, this must be viewed as an opportunity to refocus on the need for tissue validation of vwMRI for the investigation of ICAD, a feat that will prove difficult and likely rely on animal models. The burden of proof lies in such validation, and the value of vwMRI lies in its potential to identify processes that mediate disease rather than assuming there is a common pathophysiologic driver of atherosclerosis in all vascular beds.

Disclosures: Adam de Havenon-RELATED: Grant: National Institutes of HealthNational Institute of Neurological Disorders and Stroke, Comments: supported by the National Institutes of Health-National Institute of Neurological Disorders and Stroke K23NS105924.* Joseph Scott McNally—RELATED: Grant: American Heart Association, National Institutes of Health, Comments: support from the following grants: 1) American Heart Association Scientist Development Grant (Principal Investigator) 17SDG33460420; 2) American Cancer Society, Huntsman Cancer Institute grant (Principal Investigator) 129785IRG1619001IRG; 3) National Institutes of Health (Co-Investigator under D. Dennis Parker, Principal Investigator) 1R01 HL127582-01A1.* *Money paid to the Institution.

\section{REFERENCES}

1. Zwartbol MH, Geerlings MI, Ghaznawi R, et al. Intracranial atherosclerotic burden on 7T MRI is associated with markers of 
extracranial atherosclerosis: the SMART-MR study. AJNR Am J Neuroradiol 2019;40:2016-22 CrossRef Medline

2. Chan LL. Intracranial and extracranial atherosclerosis: more similar than different? AJNR Am J Neuroradiol 2019;40:2023-24 CrossRef Medline

3. Lasjaunias PL, ter Brugge KG, Berenstein A, et al. Clinical and Interventional Aspects in Children: With 102 Tables. 2nd ed. Heidelberg: Springer-Verlag; 2006

4. Resch JA, Baker AB. Etiologic mechanisms in cerebral atherosclerosis: preliminary study of $\mathbf{3 , 8 3 9}$ cases. Arch Neurol 1964;10:617-28 CrossRef Medline
(1) M.D. Alexander

Departments of Radiology and Imaging Sciences and Neurosurgery

(1D) Ae Havenon Department of Neurology University of Utah Salt Lake City, Utah

(D) Mossa-Basha Department of Radiology University of Washington Seattle, Washington

(D).S. McNally Departments of Radiology and Imaging Sciences University of Utah Salt Lake City, Utah 